\title{
SOBRE ESTRATÉGIAS E DISPOSITIVOS NORMATIVOS EM FOUCAULT: CONSIDERAÇÕES DE MÉTODO
}

\author{
ABOUT STRATEGIES AND NORMATIVE DISPOSITIVES IN FOUCAULT: \\ METHOD CONSIDERATIONS
}

Jean Francois Y Deluchey*

\begin{abstract}
Resumo: Neste artigo, busco refletir as potencialidades e dificuldades metodológicas relativas ao uso do "dispositivo" como ferramenta de investigação nas ciências sociais e sociais aplicadas. Sugiro pensar a relação entre dispositivos normativos e sujeitos de direito, a partir da analítica do poder de Michel Foucault, para quem o poder existe como feixe de relações dissimétricas coordenadas por estratégias que impactam os sujeitos em suas dimensões inter e intraindividuais. Para tanto, o uso do dispositivo - em especial no caso do dispositivo normativo - apresenta-se como importante ferramenta metodológica, na medida em que funciona como grade de análise das relações de poder, de identificação das estratégias e de seus efeitos nos sujeitos. Nas conclusões, observo que a identificação da estratégia de um dispositivo deve perpassar pela análise da lógica das relações que o compõem, para, em um segundo momento, ver de que forma e em que medida esta estratégia impacta as formas de vida dos atores que compõem o nosso campo de estudo.
\end{abstract}

Palavras-Chave: Poder; Estratégia; Dispositivo; Sujeito; Dobra.

\begin{abstract}
In this article, I try to interrogate the potentialities and methodological difficulties related to the use of the "dispositive" as a tool for research in the social sciences and applied social. I suggest to think the relation between normative dispositives and subjects to law from the Michel Foucault's analytics of power, philosopher for whom the power exists as a beam of dissymmetrical relations coordinated by strategies that impact the subjects in their dimensions inter and intraindividuals. The use of the dispositives - especially of the normative ones - presents itself as an important methodological tool, to the extent that works as analytic framework of power relations, identification of strategies and their effects on the subjects. Finally, I observe that the identification of a dispositive strategy should pass by analysis of the logic of relations that compose it, for, in a second moment, see how and to what extent this strategy impacts the ways of life of the actors that compose our field of study. Keywords: Power; Strategy; Dispositive; Subject; Fold.
\end{abstract}

\footnotetext{
* Cientista Político. Professor da Universidade Federal do Pará. Coordenador do Centro de Estudos sobre Instituições e Dispositivos Punitivos (CESIP). E-mail: jfdeluchey@gmail.com
} 


\section{INTRODUÇÃO}

Iniciemos com uma pergunta: Com quais precauções devemos abordar a relação entre sujeitos de direito, dispositivos normativos e emancipação? Esta relação passa por uma analítica do poder tal como este se apresenta enquanto expressão de uma relação interindividual (ou até de uma relação intraindividual). De antemão, temos de nos confrontar com a provocação de Michel Foucault: "Le pouvoir, ça n'existe pas" (o poder, isto não existe; FOUCAULT: 1994; 302). Foucault define o seu conceito de poder na mesma entrevista na qual define o dispositivo. Para o filósofo francês, o poder não existe em nenhum lugar específico. O chamado poder seria um "feixe de relações mais ou menos organizado, mais ou menos piramidalizado, mais ou menos coordenado" e, acrescenta Foucault: "o único problema é de se dar uma grade de análise, permitindo uma analítica das relações de poder" (FOUCAULT: 1994 [1977]; 302).

Visando a esta análise, temos de associar o poder a "uma relação de forças desigual e relativamente estabilizada, evidentemente isto implica uma diferença de potencialidade entre em cima e em baixo" (FOUCAULT: 1994 [1977]; 304. Grifo nosso). Essas relações, sejam elas de cima para baixo ou de baixo para cima $^{1}$, devem ser apreendidas por meio das estratégias que as "coordenam", diz Foucault. Para facilitar esta análise, Michel Foucault nos presenteou com uma "grade de análise", uma ferramenta conceitual a partir da qual podemos pensar com maior sutilidade as relações de poder e as estratégias de poder que as coordenam: os "dispositivos".

Se Bourdieu fala que se conhece bem um objeto a partir do momento em que a gente pode reconstruir sua gênese, apenas poderíamos abordar a questão das relações de poder a partir da análise de sua gênese (BOURDIEU; 2011 (1994): 91-135). Com Foucault, a gênese é constantemente reinventada: esta é viva e sua reconstrução não escapa, bem pelo contrário, às relações de poder que reconstroem uma hierarquia dos saberes e das memórias:

Falei que o dispositivo era de natureza essencialmente estratégica, o que supõe que se trate de certa manipulação de relações de forças, de uma intervenção racional e concertada dentro dessas relações de forças, seja para desenvolvê-las, seja para bloqueá-las, ou para estabilizá-las, utilizá-las. O dispositivo é, portanto, sempre inscrito em um jogo de poder, mas também sempre ligado a uma ou várias configurações de saber, que dele nascem, mas que igualmente o condicionam. É isto, o dispositivo: estratégias de relações de forças sustentando tipos de saber, e sustentadas por eles (FOUCAULT; 1994 [1977]: 300). 
Caso quisermos estudar as relações de poder (ou, através dessas, o universal "Estado"), devemos identificar os dispositivos que as "coordenam" e as moldam constantemente. Por sua vez, a identificação dos dispositivos não é tão simples metodologicamente e merece, portanto, uma reflexão (aqui apresentada) sobre as potencialidades epistemológicas e as dificuldades metodológicas relativas ao uso do "dispositivo" como ferramenta de investigação nas ciências sociais e ciências sociais aplicadas.

\section{OS TRÊS ELEMENTOS DO DISPOSITIVO}

Michel Foucault definiu de forma precisa o conceito de "dispositivo" em uma entrevista de 1977, intitulada "Le jeu de Michel Foucault" publicada na revista Ornicar Boletim periódico do campo freudiano, pouco depois da publicação do primeiro volume de sua História da Sexualidade intitulado A vontade de saber. Face aos psicanalistas do campo freudiano, Foucault nunca definiu melhor o que ele entendia por dispositivo, apesar de usar fartamente este conceito (sem defini-lo) nas suas aulas no Collège de France. Em 1979, este texto foi publicado em português no Brasil, no livro A microfísica do poder, sob o título: "Sobre a história da sexualidade", em que Foucault define o dispositivo da seguinte forma:

um conjunto absolutamente heterogêneo. Comportando discursos, instituições, organizações arquitetônicas, decisões regulamentares, leis, medidas administrativas, enunciados científicos, proposições filosóficas, enfim: o dito, assim como o não dito, eis os elementos do dispositivo. O dispositivo em si, é a rede que podemos estabelecer entre esses elementos (FOUCAULT: 1994 [1977]; 299).

Mais tarde na entrevista, Foucault deixa transparecer a definição de dois outros conceitos que poderiam significar alguns dos elementos discursivos e não discursivos que compõem o dispositivo, restando a saber se a soma dos dois pode exaurir os elementos suscetíveis de compor um dispositivo: a épistemè (elementos discursivos) e a instituição (elementos não discursivos). A épistemè, para Foucault:

é um dispositivo especificamente discursivo, [...] o dispositivo estratégico que permite separar dentre todos os enunciados possíveis os que poderão ser aceitáveis dentro [...] de um campo de cientificidade, e do qual poder-se-á dizer: este é verdadeiro ou falso. É o dispositivo que permite separar, não o verdadeiro do falso, mas o inqualificável cientificamente do qualificável (FOUCAULT: 1994 [1977]; $301)$. 
Quanto à instituição, significaria: "todo comportamento mais ou menos constrangido, aprendido". E Foucault conclui: "todo o social não discursivo, é a instituição" (FOUCAULT: 1994 [1977]; 301). Se, por um lado, parece claro a Foucault que todo dispositivo não discursivo significa uma instituição, nada indica a priori que o conceito épistemè recubra o conjunto dos elementos discursivos compondo um dispositivo. A épistemè, no entanto, não deve ser reduzida ao campo do discurso científico. Há de relacionála com a produção dos saberes e às relações de poder que esta produção cria, por além da simples consolidação de um "campo de cientificidade". Devemos observar que "campo de cientificidade" não significa "campo $d a$ cientificidade". Foucault, aqui, não quis apenas falar do campo científico e dos discursos que delimitam este campo específico das atividades humanas ${ }^{2}$. Trata-se de um "regime de saber" que define "a maneira pela qual o saber circula e funciona, suas relações com o poder" (FOUCAULT: 1995; 235). Assim, a cada discurso corresponde o seu próprio regime do saber, a sua "cientificidade", esta podendo ser reconhecida ou não, reprimida ou valorizada, publicizada ou não. É o sentido dado a uma obra de arqueologia que busca restaurar, na esfera intelectual e informacional, os saberes que em certa época foram assujeitados, isto é, rotulados como impróprios a compor o rol dos saberes reconhecidamente científicos e que, por via de consequência, foram esquecidos ou estigmatizados.

Situar os saberes em relação à sua historicidade e, sobretudo, a sua inserção nas lutas pelo reconhecimento que fundam os campos propícios a transformar esses saberes em relações dissimétricas de poder, certamente foi um dos maiores aportes de Foucault à história das ideias e à construção de um pensamento crítico inscrito em sua própria historicidade, isto é, em um presente no qual se reconhece a carga histórica que o estrutura. Assim, a qualquer elemento discursivo de um dispositivo corresponde uma épistemè particular, que coloca este discurso na posição que o jogo próprio das relações de poder o atribui. Este lugar, aliás, encontra-se em constante mutação e contingente às flutuações dos jogos relacionais expressos dentro de seu campo e/ou dispositivo. Tanto as épistemè (o dito) quanto as instituições (o não dito) são partes fundantes dos dispositivos e das relações de poder que os constroem e que eles "coordenam".

Além desta primeira característica do dispositivo (conjunto de elementos discursivos e não discursivos), o filósofo francês acrescenta uma segunda: entre esses elementos heterogêneos "existe um tipo de jogo, trocas de posições, modificações de funções 
que também podem ser muito diferentes" (e ao mesmo tempo podem envolver elementos expostos, publicizados e outros velados).

Finalmente, a terceira característica que define um dispositivo, last but not least, é que este designa uma espécie "de formação", que num certo momento histórico, teve por função essencial responder a uma urgência. $O$ dispositivo, portanto, tem uma função eminentemente "estratégica" (FOUCAULT: 1994 [1977]; 299). Caso quisermos resumir esta definição, talvez eu possa me arriscar e propor que o dispositivo é uma rede de elementos heterogêneos (discursivos e não discursivos, expostos e velados) cuja formação corresponde a uma função estratégica específica.

\section{A GÊNESE ESTÁ NA ESTRATÉGIA}

Caso procurarmos a gênese de um dispositivo, e talvez, mais especificamente, de um dispositivo normativo, provavelmente esta pode ser encontrada na identificação da estratégia que o funda. Mas este exercício é outro jogo perigoso: considerando que a estratégia de um dispositivo é mutante e, muitas vezes, se esconde por detrás de falsas estratégias justificadoras da existência do mesmo, a identificação analítica de um dispositivo deve ser realizada com especial cautela. Interrogado sobre qual a gênese de um dispositivo, Foucault responde identificando dois momentos para esta gênese. $O$ primeiro momento seria o da "prevalência" ou aparecimento de um objetivo estratégico; poderíamos falar de momento "fundante" do dispositivo. Os elementos discursos e não discursivos que compõem a rede do dispositivo apenas são reunidos por um motivo estratégico, isto é, por uma projeção em um devir histórico dos indivíduos e grupos sociais que avaliam este devir como desejável.

Por isto, a estratégia é provavelmente o mais importante componente do dispositivo, porque este reina na estruturação da rede formada por esses elementos. Poderíamos dizer que a estratégia é duplamente a razão do dispositivo, ela é ao mesmo tempo o motivo originário e a grade racional do dispositivo. O próprio Foucault atribui três sentidos à palavra estratégia no texto "Deux essais sur le sujet et le pouvoir" (O Sujeito e o Poder), os quais podem aplicar-se ao desenho conceitual do dispositivo:

1. "escolha dos meios empregados para se chegar a um fim; trata-se da racionalidade empregada par atingirmos um objetivo";

2. "a maneira pela qual tentamos ter uma vantagem sobre o outro"; 
3. “o conjunto dos procedimentos utilizados num confronto para privar o adversário dos seus meios de combate e reduzi-lo a renunciar à luta" (FOUCAULT; 1995: 247. Grifos do autor).

Nos três sentidos da estratégia, seja como busca de um determinado fim (1), na procura de uma distinção social (2) ou na vontade de conquistar o domínio em um referido campo (3), a estratégia estrutura o dispositivo desde a sua gênese.

O segundo momento, que garante que a rede formada se consolide no tempo enquanto "dispositivo", envolve dois processos heterogêneos que contribuem na definição da "natureza da ligação que pode existir entre esses elementos heterogêneos" que compõem o dispositivo (segunda característica da definição foucaultiana). Em relação a esta segunda característica, Foucault quis dar a precisão seguinte:

o que eu gostaria de avistar no dispositivo, é justamente a natureza da ligação que
pode existir entre esses elementos heterogêneos. Assim, tal discurso pode aparecer
certa vez como programa de uma instituição, outra vez ao contrário, como um
elemento que permite justificar e mascarar uma prática que, por sua vez, permanece
muda, ou funcionar como reinterpretação segunda desta prática, dando à mesma
acesso a um novo campo de racionalidade. Enfim, entre esses elementos, discursivos
ou não, há como um jogo, trocas de posição, modificação de funções, que podem,
também, ser muito diferentes (FOUCAULT; 1994 [1977]: 299).

Entre os elementos heterogêneos que compõem o dispositivo, um jogo relacional vai estabelecer "a natureza da ligação que pode existir entre esses elementos", a qual vai contribuir na renovação ou na fundação de um campo estratégico a partir do qual vai operar o dispositivo. A gênese dos dispositivos, para Foucault, deve se compor de dois momentos distintos. Primeiro, temos de observar a prevalência de um objetivo estratégico. Em um determinado momento, por causa de múltiplos fatores cuja articulação é complexa, um objetivo coletivo se sobressai entre as estratégias individuais ou coletivas dos atores, e este objetivo se impõe como prioritário para uma série desses atores que se dispõem, portanto, em adequar suas estratégias individuais e coletivas a uma estratégia global, que vai criar um campo estratégico e a rede entre elementos discursivos e não discursivos que compõem o dispositivo.

O segundo momento da gênese concerne à constituição do dispositivo, isto é, à fixação e à consolidação do campo de saber e das relações institucionais que transformam o dispositivo em uma unidade de elementos díspares. Michel Foucault identifica dois processos distintos, inerentes à constituição de um dispositivo. O primeiro é o de sobredeterminação 
funcional: para dar uma coerência interna aos elementos heterogêneos em beneficio da estratégia implementada, requer-se uma redefinição da função própria dos elementos que compõem o dispositivo à luz da nova estratégia pautada. De certa forma, para ter um dispositivo, precisa-se que os elementos se redefinam estratégica e funcionalmente, e que a relação entre estes também seja renovada, adequando-se e transformando-se no objetivo de maximizar, por meio desta relação, a definição funcional que cada elemento se vê atribuído no conjunto do dispositivo.

Por outro lado, esta definição funcional não é fixa e deve se transformar no tempo à luz das práticas e dos campos de saber aos quais o dispositivo está ancorado. Por isto, o segundo processo que contribui na consolidação do dispositivo é o de perpétuo preenchimento estratégico, por meio do qual os atores do dispositivo conseguem renovar continuadamente as funções estratégicas. Aliás, esta renovação pode ser intencional (novos arranjos estratégicos) ou pode ser consequência de nova configuração das práticas estratégicas. O "preenchimento estratégico", portanto, não se caracteriza por um controle absoluto dos atores sobre as suas práticas ou sobre os campos de saber. O fato de esta renovação ser "perpétua" indica que o preenchimento ocorre de forma bastante autônoma e contingente, podendo até ser oposta à intencionalidade estratégica original. Desta forma, o processo de perpétuo preenchimento estratégico abre a possibilidade de integrar elementos $a$ priori não desejados no dispositivo. Por exemplo, Foucault cita a consolidação de um "meio delinquente" como consequência indesejada de um dispositivo de encarceramento cuja estratégia original explícita visava "lutar contra a criminalidade" (FOUCAULT: 1994 [1977]; 299-300).

Se a gênese de um dispositivo pode ser encontrada no objetivo estratégico que fundou a sua criação e consolidação, pode até haver um progressivo esvaziamento da estratégia original e a caixa vazia do dispositivo novamente se "encher" de elementos estratégicos renovados. Da mesma forma, um aparente objetivo estratégico (lutar contra a criminalidade) pode ser combinado ou até mascarar um objetivo estratégico difícil de ser publicizado sem colocar em risco a própria estratégia (colocar por fora do mercado as populações indesejáveis para o mercado, produzir um "efeito de isolamento" dentro da classe operária, enfraquecer o poder de negociação dos trabalhadores no mercado de trabalho, etc.).

Por isto, a vigilância do pesquisador na identificação do dispositivo deve ser máxima. Podemos encontrar um dispositivo cuja estratégia originária ficou intocada com o tempo, mas cujas funções se encontram integralmente modificadas. Por outro lado, podemos 
observar um dispositivo cuja estratégia originária foi totalmente esvaziada e ocupada por outros objetivos estratégicos.

Também não podemos demonstrar demasiada ingenuidade na identificação da estratégia que funda o dispositivo: a estratégia explícita é, por vezes, contrária à estratégia que realmente reinou na construção do dispositivo. Uma coisa é a estratégia originária, a que leva os atores a mobilizar discursos e práticas para constituir uma rede estratégica e o seu correspondente campo estratégico de saber-poder. Outra coisa é a estratégia apresentada de forma espetacular para os atores externos ao dispositivo, a qual visa legitimar as práticas e os discursos do dispositivo e aumentar a capacidade de penetração dos elementos do dispositivo nos campos de poder e de saber, que são determinantes para a realização coletiva e contínua da verdadeira estratégia. Aliás, podemos facilmente imaginar que, pelo menos por um tempo, os objetivos estratégicos que levaram à criação do dispositivo podem até permanecer invisíveis enquanto as práticas governamentais que o compõem não se encontrarem suficientemente consolidadas ou institucionalizadas.

Afinal, podemos resumir o que seria a gênese, o processo de construção de um dispositivo normativo. Primeiro, de forma mais inconsciente ou contingente de que consciente ou intencional, prevalece em um determinado campo de práticas, instituições e saberes certo objetivo estratégico que vai contribuir na refundação das funções, das práticas e das estratégias individuais e coletivas dos atores sociais interessados. A ação desses atores individuais e coletivos vai criar uma rede estratégica que, à medida de sua consolidação, vai se transformar em dispositivo normativo por meio de dois processos: uma sobredeterminação funcional, que vai servir de grade referencial para a transformação dos saberes, práticas e instituições que interessam na perspectiva da estratégia pré-definida, e um perpétuo preenchimento estratégico que vai resultar da ação múltipla e nem sempre conjunta dos atores do dispositivo, e das transformações estratégicas que podem ocorrer no decorrer do tempo.

\section{DISPOSITIVO E SUBJETIVAÇÃO}

Em relação aos fenômenos normativos, sejam eles propriamente jurídicos ou político-institucionais, o que esta definição e identificação do dispositivo pode acrescentar na sua análise? Primeiro, devemos lembrar com Marx, Durkheim, Weber, Bachelard e Bourdieu, que a vida social tem de ser explicada não pelas concepções de seus participantes, mas pelas causas estruturais e relacionais que escapam à sua consciência. Nas palavras de Crozier e 
Friedberg, retomando às principais teses de Bachelard expostas no livro A Formação do Espírito Científico:

\begin{abstract}
Para poder observar, comparar, analisar e interpretar os comportamentos dos atores que ele observa, o pesquisador deve, antes de mais nada, questionar a maneira como eles se apresentam primeiramente para ele, e como os próprios atores se percebem e descrevem. O pesquisador deve ser capaz de se colocar numa posição de recuo e de distância crítica, permitindo-lhe desta forma romper com a realidade sensível, com as categorias do senso comum (as dos atores tanto quanto das suas próprias), e extrair dos dados observados esse caráter de "evidência" que, muitas vezes, elas revestem no olhar dos participantes (CROZIER \& FRIEDBERG: 1977; 455).
\end{abstract}

Com efeito, os fatos sociais somente podem ser explicados quando forem sistematicamente construídos contra o senso comum, bem como, objetivados em um sistema de relações de tal modo que as relações estruturais objetivas entre os elementos fenomênicos necessitem e expliquem o comportamento dos elementos da relação construída entre os elementos.

Como explica Frédéric Vandenberghe:

\begin{abstract}
Nesta concepção relacional, o particular não é mais subsumido no geral, como no caso do silogismo aristotélico, mas uma inter-relação funcional ou dialética é estabelecida entre ambos de modo tal que o particular, que é sobredeterminado pela teoria, aparece como a síntese concreta de um conjunto de relações gerais. ' $O$ conceito não mais descarta desdenhosamente os particulares que especificam os conteúdos que ele subsume, mas, ao contrário, busca descobrir a necessidade da manifestação e a conexão dos próprios particulares. $O$ que o conceito propõe, assim, é uma regra universal que nos permite compor e combinar o elemento particular em pessoa' (Cassirer, [1910] 1994: 25). [...] Como resultado da aplicação do modo de pensamento relacional, "os conceitos cientificos não mais aparecem como imitações de existências coisificadas, mas como símbolos representando ordens e articulações funcionais presentes na realidade" (Cassirer, [1906] 1971: 3). $\mathrm{Na}$ medida em que a realidade dos objetos se dissolveu em um mundo de relações racionais, podemos de fato dizer, com Bachelard e Hegel, que "o real é racional" [...], bem como, com Cassirer e Bourdieu, que "o real é relacional" (VANDENBERGHE: 2013; 18-19) ${ }^{3}$.
\end{abstract}

Ademais, na medida em que os instrumentos e técnicas da pesquisa empírica são, como disse Bachelard, "teoremas realmente reificados", todas as operações da pesquisa sociológica - da formulação de um questionário à sua codificação e análise estatística - têm de ser consideradas como "várias teorias em ação", na expressão de Bourdieu, Chamboredon e Passeron (2007). Um conhecimento acurado daquilo que se faz sobre e com os fatos, bem como, do que os fatos podem ou não fazer, é, portanto, o primeiro requisito da perspectiva sociológica.

R. Fac. Dir. UFG, v. 40, n.2, p. 175-196, jul. / dez. 2016 
Desta forma, é preciso o pesquisador realizar um esforço metodológico particular no objetivo de enxergar a ação dos dispositivos normativos em vários contextos, bem como, sua influência nos atores sociais, especialmente para os atores que não participam do desenho estratégico do dispositivo. Para além disto, não apenas devem ser estudados os dispositivos normativos em si (normas jurídicas, políticas públicas, práticas governamentais, especialmente judiciárias), mas também os impactos dos mesmos na dimensão intraindividual, isto é, dentro de cada indivíduo que vai interiorizando e naturalizando os comandos sociais e os referenciais destes dispositivos e acaba se autorregulando, se autocontrolando e, finalmente, se moldando seguindo a lógica dos referidos dispositivos. Aqui deve ser mobilizada intelectualmente a imagem da "dobra" que Foucault emprestou a Gilles Deleuze, que por sua vez, usou desta imagem para representar os processos de subjetivação. Deleuze nos explica como funciona um processo de subjetivação e como sua análise é fundamental para o estudo da vida social e de seus correspondentes dispositivos normativos, inclusive, os jurídicos. Para o sociólogo Bernard Lahire, que na sua metodologia sociológica empresta muito à filosofia foucaultiana e deleuziana:

O que sugere utilmente a metáfora da dobra, é também o fato que o "interior" apenas é um "exterior" no estado dobrado. Não tem, para os indivíduos, nenhuma existência possível fora do tecido social. E mais do que isto, as fibras deste tecido, que se cruzam e se entrecruzam, são constitutivas de cada indivíduo. [...] O mito da interioridade, que faz desta uma realidade autônoma, anterior a qualquer forma de experiência, encontrou-se completamente derrubada pelas ciências sociais (LAHIRE: 2013; 16).

O dispositivo age, assim, sobre as estratégias dos grupos e dos indivíduos, mas pode servir de ferramenta metodológica para entender de que forma e com qual extensão ou impacto os indivíduos encontram-se obrigados a se adequar ao processo normativo do dispositivo. Nesta dimensão, o processo normativo do dispositivo aparenta-se a um processo normalizador, muito mais de que um processo normatizador. Acredito metodologicamente importante, hoje em dia, identificar os impactos e as consequências microfísicos dos dispositivos normativos, especialmente em um ambiente neoliberal que busca fazer do mercado o lugar de veridição de nossos atos (FOUCAULT; 2008). Neste ponto, há de lembrar a distinção entre a normação (disciplinar, liberal e jurídico-dedutiva) e a normalização (reguladora, neoliberal e radical-utilitarista) operada por Foucault nas aulas reunidas no livro Segurança, Território, População (FOUCAULT; 2009: 73-103). 
Para Foucault, cada sistema legal se relaciona com um sistema de normas, mas a norma é específica do mundo sólido e dos espaços confinados da disciplina (escola, fábrica, prisão). Neste sentido a governamentalidade disciplinar (liberal ou jurídico-dedutiva) constitui mais um exercício de normação fundado na norma, de que uma normalização, já que "o que é fundamental e primeiro na normalização disciplinar não é o normal e o anormal, é a norma" (FOUCAULT; 2009: 75). Por sua vez, segundo a arte neoliberal de governar, busca-se normalizar as pessoas a partir de dispositivos reguladores. O que importa, na sociedade neoliberal, é definir o normal e o anormal, e deduzir daí as normas e instituições necessárias à instauração de uma governamentalidade, uma arte de governar que vai passar não apenas pelo Estado, mas também vai penetrar as relações interindividuais e intraindividuais, por meio do controle recíproco e do autocontrole dos indivíduos.

\section{O Dispositivo, A ANÁlise COGNITIVA E A ABORDAGEM ESTRATÉGICA}

Para que os indivíduos e grupos moldem seus comportamentos aos dispositivos que se expressam sobre e dentro deles, importa observar a relação entre o caráter explícito de um dispositivo ou de uma norma e seus efeitos práticos, inclusive nos processos de subjetivação. Aqui, a teoria sobre dispositivos pode ser relacionada com outra escola de pensamento: a que, seguindo Bruno Jobert, Pierre Muller, entre outros, trata de realizar uma análise cognitiva das políticas públicas. Em primeiro lugar, considero que as políticas públicas vão além da simples noção de "produto" ou "programa" de ação governamental, e se aproximam muito dos fenômenos sociais que propomos tentar identificar a partir do conceito de dispositivo. Para ser mais preciso, seguindo as palavras de Muller e Surel:

[...] para que uma política pública "exista", é necessário que as diferentes declarações e/ou decisões sejam reunidas em um quadro geral de ação que funcione como uma estrutura de sentido, isto é, que mobilize elementos de valor e de conhecimento, bem como instrumentos de ação particulares, visando à realização de objetivos construídos pelos intercâmbios entre atores públicos e privados (MULLER \& SUREL; 1998: 18-19. Tradução nossa).

Os elementos em comum desta definição cognitiva da política pública com a definição foucaultiana do dispositivo são evidentes. A política pública mobiliza "elementos de valor e de conhecimento", bem como, "instrumentos de ação particulares”, da mesma forma 
que o dispositivo mobiliza elementos discursivos (epistemes) e não discursivos (instituições) para compor sua rede. Esta rede, segundo elemento de definição do dispositivo, se transforma na definição da política pública por Muller e Surel em "estrutura de sentido" e em "intercâmbios entre atores públicos e privados", os quais acrescidos dos elementos discursivos e não discursivos que acabei de evocar. Para completar esta definição, falta um objetivo estratégico: a definição de Muller e Surel descreve a política pública como um “quadro geral de ação [...] visando à realização de objetivos construídos pelos intercâmbios". Assim a definição de uma política pública pelos padrões da análise cognitiva apresentada por esses autores, encontra no dispositivo uma precisão conceitual que faz do dispositivo uma ferramenta extremamente adequada ao estudo das políticas públicas, inclusive das políticas legislativas e administrativas que ofertam ao campo judiciário seu quadro normativo de ação.

A dimensão cognitiva da política pública é, nesta ótica, de suma importância. $\mathrm{Na}$ análise cognitiva, a própria política pública vira arena política de debate, de negociação e de construção do sentido da ação governamental lato sensu. Desta forma, podemos fugir de uma visão um tanto utilitarista acerca da ação governamental vista essencialmente através de uma análise sequencial das políticas públicas, a qual subestima a construção de um novo sentido construído a partir de referentes temáticos, geográficos ou político-administrativos, para se concentrar prioritariamente na execução das ações governamentais ao detrimento da construção do espaço próprio das políticas públicas. A nosso ver, o interesse científico maior da análise de políticas públicas consiste justamente em que esse espaço próprio está em constante negociação e reforma entre atores públicos, e entre estes e os atores privados, quaisquer que sejam.

Muller e Surel insistem muito no livro L'analyse des politiques publiques sobre o que representa para eles a primeira das três grandes rubricas através das quais podemos abordar a definição do conceito "política pública", a saber, a construção de "um quadro normativo de ação", complementado pelas outras duas rubricas: a "expressão da potência pública" e a tendência das políticas públicas em constituir uma "ordem local” (MULLER \& SUREL: 1998; 16-23).

Segundo os dois autores, construir um "quadro normativo de ação", aliás, não significa que "todas as medidas referentes devam ser obrigatoriamente reunidas em um quadro normativo e cognitivo perfeitamente coerente. Se tal fosse o caso, isto, sem dúvida, significaria que não existiria nunca uma "verdadeira" política pública" (MULLER \& SUREL: 1998; 19. Tradução nossa). Para atender os objetivos de análise, temos que tentar desvendar R. Fac. Dir. UFG, v. 40, n.2, p. 175-196, jul. / dez. 2016 
as "lógicas de ação" e as "lógicas de sentido" presentes nos processos de elaboração e de implementação das políticas.

Com a "expressão da potência pública", Muller e Surel entendem que "uma política governamental integra elementos de decisão ou de alocação de recursos de natureza mais ou menos autoritária ou coercitiva" (MULLER \& SUREL: 1998; 20. Tradução nossa). Estes elementos de decisão e de alocação de recursos só podem ser explicados e entendidos a partir da identificação e da análise da estratégia atual expressa por meio do dispositivo, lembrando também de sempre buscar identificar tanto a "sobredeterminação funcional" pesando sobre os atores e suas decisões, como o preenchimento estratégico que caracteriza o dispositivo naquele momento. Por isto, a coerção não pode ser vista como planejada e exercida de cima para baixo, e devemos fugir de considerações ingênuas envolvendo as relações entre soberano e cidadão no Estado de direito.

Claro, explicam Muller e Surel, a coerção não escapa das outras políticas públicas através de processos discriminatórios (positivos ou negativos) que diferenciam os beneficiários e os não beneficiários de uma política, e neste contexto, "as políticas governamentais constroem relações dissimétricas entre o Estado, que modificam o ambiente jurídico dos indivíduos, e os cidadãos, que estes sejam beneficiários ou "vítimas" das regulamentações". Por outro lado, Muller e Surel nos pedem precaução na análise de tais fatos ligados à expressão da potência pública: "afirmar a especificidade da ação do Estado não deve desembocar em uma reificação da potência pública em um bloco homogêneo e autônomo". O próprio Estado é geralmente tão permeado pelos interesses do setor privado, que considerações sobre a discriminação e a expressão da potência pública nas políticas públicas sempre devem estar acompanhadas de uma "interrogação constante acerca da natureza evolutiva do Estado e das relações entre espaço público e privado" (MULLER \& SUREL: 1998; 21. Tradução nossa). Aqui, Muller e Surel chegam a conclusões parecidas as de Foucault sobre a existência de um perpétuo preenchimento estratégico nos dispositivos normativos.

No que tange à terceira rubrica "uma política pública constitui uma ordem local", Muller e Surel se referem à definição dada à noção de "ordem local” pelo sociólogo Erhard Friedberg: "uma construção política relativamente autônoma que opera ao seu nível a regulação dos conflitos entre os interessados" (FRIEDBERG: 1997; 26. Tradução nossa). Desta forma, concluem Muller \& Surel, "para estudar uma política pública, ter-se-á de levar em consideração o conjunto dos indivíduos, grupos ou organizações cuja posição está afetada 
pela ação do Estado em um referido território" (MULLER \& SUREL: 1998; 22. Tradução nossa).

No que tange à análise das práticas judiciárias, bem como no estudo das relações interinstitucionais identificadas através dos discursos dos atores sociais, é possível seguir os passos metodológicos da análise estratégica tal como apresentada por Crozier e Friedberg no seu livro $O$ ator e o sistema. Esse tipo de análise consiste em estudar os construídos e os jogos que moldam, nas organizações, as estratégias individuais e coletivas dos atores sociais, tentando especialmente situar as mesmas no campo dos constrangimentos institucionais e ambientais onde são exercidas. Para eles, a abordagem estratégica:

[...] somente será capaz de descobrir o peso desses constrangimentos, tanto em relação aos atores quanto ao conjunto que eles formam, reconstruindo - numa perspectiva fenomenológica limitada - a lógica e a racionalidade próprias das relações e interações que subentendem esse conjunto. De maneira necessária e inelutavelmente contingente, consiste cada vez em descobrir as características, a natureza e as regras do jogo que estruturam as relações entre os referidos atores, e logo remeter aos modos de regulação pelos quais esses jogos se articulam uns com os outros e operam dentro de um sistema de ação (CROZIER \& FRIEDBERG: 1977; 452. Tradução nossa).

Acredito que procurar identificar qual é a estratégia de um dispositivo deva passar pela análise de "a lógica e a racionalidade próprias das relações e interações que subentendem esse conjunto", como falam Crozier e Friedberg. A partir deste estudo, podemos ir além na nossa avaliação de uma lógica sistêmica singular ou, ao contrário, a lógicas sistêmicas plurais apenas articuladas em volta de objetivos inter-relacionados. Para os dois autores, um sistema é "um conjunto constituído como um campo estruturado - não neutro - cujos diferentes elementos têm condutas coordenadas e interdependentes" (CROZIER \& FRIEDBERG: 1977; 227. Tradução nossa). Na lógica sistêmica, faz-se o postulado prévio da existência do sistema e de que, mesmo se relacionando com outros sistemas e subsistemas sociais, esse sistema tem autonomia interna e fronteiras institucionais ou relacionais externas. Ao contrário, o dispositivo não se define por limites externos, não reivindica uma autonomia particular dentro do campo social: ele propõe apenas ao pesquisador desenvolver, em relação a alguns fenômenos observados, quais seriam as articulações racionais e os efeitos de constrangimento ligados à busca por um número indeterminado de atores, de interesses estratégicos específicos.

Com efeito, como dizem Crozier e Friedberg, mesmo sabendo que: 
[...] todo sistema de ação se constitui através das relações de poder entre atores, os quais buscam controlar zonas de incerteza pertinentes em relação aos problemas a ser resolvidos, esta formulação geral não lhe informa sobre a dinâmica particular e contingente desses confrontos de poder, nem sobre a configuração específica de atores envolvidos, e nem sobre a extensão de seus campos estratégicos e, juntos com estes, sobre os limites do sistema cuja existência ainda precisa ser demonstrada e analisada (CROZIER \& FRIEDBERG: 1977; 453. Tradução nossa).

Nesta perspectiva, enquanto ferramenta ou método epistemológico, o conceito de dispositivo nos convida a procurar, antes de qualquer coisa, identificar a estratégia que possa dar um sentido a certas práticas e discursos sociais, e analisar, num segundo momento, de que forma e em que medida esta estratégia constrange e impacta sobre as formas de vida interessadas na consecução da referida estratégia.

\section{QUAL ESTRATÉGIA POR QUAIS ATORES?}

Reside aqui, a nosso ver, a principal dificuldade da identificação de um dispositivo: determinar a estratégia que efetivamente sustenta e orienta a formação de certo dispositivo. Sem dúvida, como reivindica para si mesmo o próprio Foucault: "Quando eu falo de estratégia, eu levo o termo a sério: para que certa relação de forças possa não apenas se manter, mas também se acentuar, se estabilizar, ganhar maior espectro, é necessário que tenha uma manobra [manœuvre]" (FOUCAULT: 1994 [1977]; 309).

Aqui aparece outro problema: se existe manobra ou manipulação, esta vem de quem? Esta manobra se expressa de cima para baixo? E qual a relação com a estrutura social da dominação? A entrevista de Foucault de 1977 junto aos psicanalistas do campo freudiano nos informa melhor sobre isto. Foucault admite que certas estratégias seriam "estratégias sem sujeito". Isto significaria que existem certas estratégias "mais ou menos coordenadas", são expressas em feixes abertos de relações de poder "mais ou menos organizados", de maneira que, diz ele, "se obtém uma estratégia global, coerente, racional, mas em relação à qual não podemos mais dizer quem a concebeu" (FOUCAULT: 1994 [1977]; 306, tradução nossa).

Esta estratégia, aliás, pode ser relacionada com a luta de classes. Para Foucault, podemos afirmar que a burguesia tornou-se classe dominante a partir do desenvolvimento de estratégias de classe:

Podemos inclusive dizer que é a estratégia que permite à classe burguesa de ser a classe burguesa, e de exercer a sua dominação. Mas que seja a classe burguesa que, ao nível de sua ideologia ou de seu projeto econômico, e como uma espécie de 
sujeito ao mesmo tempo real e fictício, tem inventado e imposto pela força essa estratégia à classe operária, eu acho que isto, não podemos dizê-lo. [...] O objetivo existia, portanto, e a estratégia se desenvolveu, com uma coerência cada vez maior, mas sem que tenhamos que supor um sujeito detentor da lei e enunciando-a sob a forma de um "tu deves, tu não deves" (FOUCAULT: 1994 [1977]; 307. Tradução nossa).

Aí, podemos ter alguma divergência maior entre o pensamento foucaultiano e, como diria Nikos Poulantzas, "um certo marxismo". Nesta disputa podemos, com Marx, arbitrar em favor de Foucault ${ }^{4}$. Não existe um sujeito histórico coletivo detentor de um poder de classe que impõe a sua dominação de cima para baixo sobre um sujeito histórico sem poder de classe, porque sem "consciência de classe" (a força do dominado mais numeroso passaria pela consciência de sua força). Foucault, aliás, nem fala de interesse de classe, mas de "necessidade estratégica" ou "problema”. Por outro lado, lembro, Foucault diz levar "a sério" o termo de estratégia, e enxerga nela uma "manobra", isto é, uma procura de efeitos de poder.

Existem, a nosso ver, três proposições correlatas a esta hipótese da "estratégia sem sujeito". Primeira proposição, o indivíduo ou grupo social dominado contribui de certa forma à dominação, justamente porque ele aceita a classificação discursiva da épistémè e assimila as naturalizações das instituições nas quais ele se encontra inserido e penetrado. $\mathrm{O}$ indivíduo ou grupo dominado também é ator social; ele faz parte de (e não é apenas subjugado por) dispositivos de dominação social que lhe outorgam em grande parte (mas não exclusivamente) a sua distinção/posição social, bem como, sua capacidade de intervenção no social. É neste sentido que Foucault escreve o seguinte em relação à piramidalização do sistema feudal:

[...] é certo que o poder dos reis da França, e os aparelhos de Estado que eles constituíram aos poucos a partir do século XI, tiveram como condição de possibilidade o enraizamento nos comportamentos, nos corpos, nas relações locais de poder, nas quais não se deveria enxergar uma simples projeção do poder central (FOUCAULT: 1994 [1977]; 304. Tradução nossa).

Da mesma forma que Pierre Bourdieu apresentaria depois nos seus estudos sociológicos, e em particular em $A$ dominação masculina, Foucault faz a hipótese que não existe dominação pura. O dominado sempre contribui na dominação, seja consciente ou inconscientemente. A dominação para Foucault é uma "situação estratégica mais ou menos adquirida e solidificada num conjunto histórico de longa data entre adversários" (FOUCAULT; 1995: 249). A dominação implica relações de poder. Não existe poder 
exercido de um sobre outro, mas existem relações de poder, o que implica uma reciprocidade entre indivíduos livres e, a priori, iguais. Esta é a diferença que Foucault estabelece entre relação de violência (onde se expressa a pura violência de um sobre outro) e a relação de poder que implica reciprocidade. Diz Foucault:

\begin{abstract}
Uma relação de violência age sobre um corpo, sobre as coisas; ela força, ela submete, ela quebra, ela destrói; ela fecha todas as possibilidades; não tem, portanto, junto de si, outro polo senão aquele da passividade; e, se encontra uma resistência, a única escolha é tentar reduzi-la. Uma relação de poder, ao contrário, se articula sobre dois elementos que lhe são indispensáveis por ser exatamente uma relação de poder: que "o outro" (aquele sobre o qual ela se exerce) seja inteiramente reconhecido e mantido até o fim como o sujeito de ação; e que se abra, diante da relação de poder, todo um campo de respostas, reações, efeitos, invenções possíveis. [...] O poder só se exerce sobre "sujeitos livres", enquanto "livres" - entendendo-se por isso sujeitos individuais ou coletivos que têm diante de si um campo de possibilidade onde diversas condutas, diversas reações e diversos modos de comportamento podem acontecer. Não há relação de poder onde as determinações estão saturadas - a escravidão não é uma relação de poder (FOUCAULT; 1995: 243-244. Grifo nosso).
\end{abstract}

As relações de poder exigem reciprocidade, isto é, uma igualdade reconhecida entre os participantes ${ }^{5}$. Esta igualdade, por sua vez, significa que as relações de poder são marcadas por uma luta constante para ampliar ou reduzir os efeitos de poder, visando o sucesso ou o fracasso das estratégias de cada ator. Sabendo que, nos dispositivos, as próprias estratégias são campo de luta, podemos entender também, em parte, como os dispositivos são marcados por processos contínuos de preenchimento estratégico, a tal ponto que podemos encontrar dispositivos cuja principal estratégia hoje é a estratégia literalmente oposta à estratégia que levou à criação deste mesmo dispositivo.

Segunda proposição à hipótese da "estratégia sem sujeito": dificilmente terá apenas um sujeito coletivo enquanto organizador específico de uma dominação que se expressaria por meio dos dispositivos. Diz Foucault:

no século XIX, por meio de todos os tipos de mecanismos ou de instituições parlamentarismo, difusão da informação, edição, exposições universais, Universidade - o poder burguês pôde elaborar grandes estratégias, sem que por este motivo se precise supor um sujeito (FOUCAULT: 1994 [1977]; 310. Tradução nossa).

Por outro lado, é bom lembrar que pode haver apenas um sujeito coletivo ou individual em uma relação de violência, onde o outro é subjugado pela força e, portanto, aniquilado enquanto sujeito. Não procurar o sujeito da dominação pode até ser uma técnica 
epistemológica válida, por nos permitir nos afastar da busca por conclusões de pesquisa inviáveis, pelo menos no plano propriamente científico.

Terceira proposição, decorrente da segunda, ter como método particular de pesquisa identificar os dispositivos, tem a grande vantagem de focar sobre a relação de poder em si, e sobre a maneira segundo a qual ela se materializa em estratégias, em épistémè e em instituições. Ora, já evoquei o fato de que existem dois lugares de expressão na relação de poder (o que traz ainda maior riqueza conceitual ao "dispositivo"): uma dimensão extraindividual e uma dimensão intra-individual.

Primeiro, na dimensão extra-individual, podemos ter efeitos de poder se expressando em relação a um indivíduo ou um grupo, vítima da estratégia em curso no dispositivo. Apesar de concernir a indivíduos a priori iguais e a uma relação que implica o princípio de reciprocidade, a relação de poder remete a uma estratégia visando vantagens, distinções e posições. Enquanto relação essencialmente dissimétrica, a relação de poder remete assim à busca de efeitos de poder de um indivíduo ou grupo sobre outro (segundo as três modalidades já evocadas de estratégia: busca de um determinado fim, procura de distinção social, conquista de domínio).

Nesta perspectiva, é muito difícil identificar o ator individual ou coletivo que estaria à origem da construção estratégica. Lembremos que segundo Foucault, o poder é "um feixe de relações mais ou menos organizado, mais ou menos piramidalizado, mais ou menos coordenado" (FOUCAULT: 1994 [1977]; 302). Digamos que um dispositivo de poder se constrói de forma progressiva, a partir da aparição e reunião em feixe de algumas estratégias, buscando para si alguns efeitos de poder que, contingencialmente, encontram sua coerência e sua força coletiva para fundar um dispositivo novo ou para modificar um antigo dispositivo que algum jogo de forças ou alguma "manobra" fez entrar em obsolescência. Por isso, com Foucault, acredito que melhor valha procurar as estratégias de que os sujeitos por trás das mesmas.

Ademais, há uma relação de criação recíproca entre a estratégia e os atores que participam deste jogo social, o que revela mais uma dimensão heurística do dispositivo. Por isto Foucault afirma, em relação à dominação burguesa na ordem capitalista: "entre a estratégia que fixa, reconduz, multiplica, acentua as relações de força, e a classe que se encontra dominante, você tem uma relação de produção recíproca" (FOUCAULT; 1994 [1977]: 307. Tradução nossa). Esta observação teórica revela-se muito importante par abordar a segunda dimensão das relações de poder que modifica consideravelmente nosso olhar e 
nosso uso do dispositivo: a dimensão intra-individual. Vale aqui retratar uma parte do diálogo entre Michel Foucault e Jacques-Alain Miller na entrevista de 1977 para a revista Ornicar:

\footnotetext{
J.-A. Miller: Afinal, quem são para ti os sujeitos que se opõem?

M. Foucault: Apenas é uma hipótese mas eu diria: todo mundo a todo mundo. Não existem, imediatamente entregues, sujeitos entre os quais um seria o proletariado e o outro a burguesia. Quem luta contra quem? Lutamos todos contra todos. E sempre há algo em nós que luta contra outra coisa em nós.

J.-A. Miller: Isto significa que apenas teria coalizões transitórias, entre as quais algumas desmoronariam imediatamente, enquanto outras durariam; mas, finalmente, o elemento primeiro e último, são os indivíduos?

$M$. Foucault: Sim, os indivíduos e até os sub-indivíduos.
}

Neste diálogo, Foucault abre outra dimensão para o uso do conceito dispositivo, o qual pode também esclarecer os conflitos de nossas individualidades enquanto pluralidades. Esta dimensão específica, intra-individual, do dispositivo e do poder enquanto feixe de relações, traz a nossa atenção sobre a possibilidade de efeitos de poder que se expressariam dentro de nós, e sobre a possibilidade de efeitos de reciprocidade entre uma dimensão interna e externa aos indivíduos nos efeitos de poder e nos dispositivos. Caberá a posterior estudo a análise desta dimensão intra-individual que o filósofo Gilles Deleuze chama de "dobra", que Raquel Rolnik chama de "marcas", que o sociólogo Bernard Lahire chama de "dobras subjetivas do social" e que deve nos ajudar a entender melhor de que forma os dispositivos normativos ecoam hoje em dia nos processos de subjetivação dos indivíduos sem que, portanto, possamos defini-los, de forma sistemática, como "sujeitos de direito".

\section{REFERÊNCIAS}

AGAMBEN, G. O que é o contemporâneo? E outros ensaios, Chapecó (SC): Argos. 2009.

BOURDIEU, P. CHAMBOREDON, J.-C. PASSERON, J.-C. Ofício de Sociólogo. Metodologia da pesquisa na sociologia. Petrópolis (RJ): Vozes. 2007.

BOURDIEU, P. Razões Práticas. Sobre a teoria da ação. Campinas: Papirus. 2011 (1994).

CROZIER, M. FRIEDBERG, E. L'acteur et le système. Paris : Seuil. 1977.

DELEUZE, G. "Qu'est-ce qu'un dispositif? " In DELEUZE, G. (org.). Michel Foucault philosophe. Rencontre internationale, Paris, 9, 10, 11 janvier 1988. Paris : Seuil. 1989. Traduzido em português por Ruy de Souza Dias e Helio Rebello (março 2001). Disponível em: http://intermidias.blogspot.com.br/2012/01/o-que-e-um-dispositivo-por-gilles.html. Acessado em 21 de agosto de 2015. 
FOUCAULT, M. "Le jeu de Michel Foucault” In Foucault (Michel), Dits et Écrits 1954-1988, Vol. III "1976-1979". Paris : Éditions Gallimard. p. 298-329. 1994. Originalmente publicado em Ornicar? Bulletin périodique du champ freudien, n.10, p. 62-93, julho 1977.

. "O sujeito e o poder". In DREYFUS, H. RABINOW, P. Michel Foucault, uma trajetória filosófica: para além do estruturalismo e da hermenêutica. Rio de Janeiro: Forense Universitária. p. 231-249, 1995. Nascimento da Biopolítica. São Paulo: Martins Fontes, 2008. . Segurança, Território, População. São Paulo: Martins Fontes, 2009.

FRIEDBERG, E. Le pouvoir et la règle. Dynamiques de l'action organisée, Paris : Seuil, 1997.

MARX, K. Le 18 Brumaire de Napoléon Bonaparte. Paris: Éditions Science Marxiste. 2010 [1869].

MULLER, P. SUREL, Y. L'analyse des politiques publiques. Paris : Montchrestien. 1998.

RANCIÈRE, J. O mestre ignorante. Cinco lições sobre a emancipação intelectual. Belo Horizonte: Autêntica Editora. 2011 [1987].

VANDENBERGHE, F. "O real é relacional": uma análise epistemológica do estruturalismo gerativo de Pierre Bourdieu". Tradução não publicada de Gabriel Peters. Disponível em: <http://sociofilo.iesp.uerj.br/wp-content/uploads/2011/03/Orealerelacional-vandenberghe.pdf>. Acessado em 20/05/2013.

\footnotetext{
${ }^{1}$ Diz Foucault: "para que tenha movimento de cima para baixo, tem que ter ao mesmo tempo uma capilaridade de baixo para cima" (FOUCAULT; 1994 [1977]: 304).

2 Pierre Bourdieu definiu melhor o conceito de campo, tal como entendemos aqui: "descrevo o espaço social global como um campo, isto é, ao mesmo tempo, como um campo de forças, cuja necessidade se impõe aos agentes que nele se encontram envolvidos, e como um campo de lutas, no interior do qual os agentes se enfrentam, com meios e fins diferenciados conforme sua posição na estrutura do campo de forças, contribuindo assim para a conservação ou a transformação de sua estrutura" (BOURDIEU: 2011 [1994]; 50. Grifo do autor).

${ }^{3}$ As duas citações de Frédéric Vandenberghe correspondem, seguindo a ordem do texto, às seguintes referências: 1) Cassirer, E. [1910] 1994. Substanzbegriff und Funktionsbegriff. Untersuchungen über die Grundfragen der Erkenntniskritiek. Darmstadt: Wissenschaftliche Buchgesellschaft. 2) Cassirer, E. [1906] 1971. Das Erkenntnisproblem in der Philosophie und Wissenschaft derneuere Zeit, Band 1. Darmstadt: Wissenschaftliche Buchgesellschaft.

${ }^{4}$ Karl Marx reconheceu uma duplicidade na definição das classes sociais. Assim, teria uma definição que poderíamos chamar de "sociológica", e tem outra que poderíamos designar como "teórico-política". No $O 18$ Brumário de Luís Bonaparte, Marx descreve a classe dos "pequenos camponeses”, na França dos anos 1850, no seguintes termos: "Na medida em que milhões de famílias camponesas vivem em condições econômicas que as separam umas das outras, e opõem o seu modo de vida, os seus interesses e sua cultura aos das outras classes da sociedade, estes milhões constituem uma classe. Mas na medida em que existe entre os pequenos camponeses apenas uma ligação local e em que a similitude de seus interesses não cria entre eles comunidade alguma, ligação nacional alguma, nem organização política, nessa exata medida não constituem uma classe". (MARX: 2010/1869; 279-280, grifo nosso).

${ }^{5}$ É o sentido da reflexão sobre a igualdade das inteligências que Jacques Rancière escreve em $O$ mestre ignorante: "Diferença e desigualdade reinam aí, como na configuração de todos os outros órgãos do corpo
}

R. Fac. Dir. UFG, v. 40, n.2, p. 175-196, jul. / dez. 2016

ISSN 0101-7187 
Sobre Estratégias e Dispositivos Normativos em Foucault [...]

humano. Tanto quanto pesa o cérebro, vale a inteligência. [...] Nesse caso os espíritos superiores - isso é, os cérebros superiores - de fato comandariam os espíritos inferiores, como o homem comanda os animais. Se assim o fosse, simplesmente ninguém discutiria a desigualdade das inteligências. Os cérebros superiores não se dariam ao trabalho inútil de demonstrar sua superioridade a cérebros inferiores - incapazes, por definição, de compreendê-los. Contentar-se-iam em dominá-los” (RANCIÈRE, 2011/1987: 74). 
Artigo recebido em 14 de agosto de 2016 e aceito em 21 de dezembro de 2016 